\title{
ESTUDO FITOQUÍMICO DA MAMONA: USO DA TÉCNICA DO LABORATÓRIO
} ROTACIONAL ADAPTADO

\author{
PHYTOCHEMICAL STUDY OF CASTOR BEAN: USE OF THE ADAPTED \\ ROTATIONAL LABORATORY TECHNIQUE
}

\author{
ESTUDIO FITOQUÍMICO DE LO RICINO: USO DE LA TÉCNICA DE \\ LABORATORIO ROTACIONAL ADAPTADO
}

Francisco José Mininel* (i)

\begin{abstract}
RESUMO
Este trabalho propõe uma adaptação à metodologia ativa chamada "Laboratório Rotacional" e suas práticas na educação básica (Ensino Híbrido). Partimos de um questionamento inicial dos alunos sobre a toxicidade da espécie vegetal Ricinus communis L., conhecida popularmente como mamona. Esse questionamento se constituiu num Tema Gerador de aprendizagem com o objetivo principal de identificar no pó das folhas da espécie vegetal, os princípios ativos responsáveis pela toxicidade e aprender a partir da abordagem experimental, conceitos de Química Orgânica. A fim de buscar resposta ao questionamento inicial, os alunos rotacionavam entre a sala de aula tradicional e os laboratórios de informática e de Ciências. Dessa forma, os alunos pesquisaram sobre a espécie e realizaram testes químicos para verificar a presença de constituintes químicos no pó das folhas. Ao se pensar no Laboratório Rotacional como uma prática, devemos considerar o papel fundamental da tecnologia, bem como a mudança de papel do professor que se torna o mediador do processo. Observou-se engajamento durante a execução das atividades, a autonomia, a criatividade, a motivação na participação das aulas e o aprender de forma colaborativa. Verificou-se que a metodologia ativa Laboratório Rotacional foi importante para a aprendizagem de conceitos químicos e permitiu que os alunos respondessem ao questionamento inicial sobre a toxicidade da espécie vegetal.
\end{abstract}

Palavras-chave: Ricinus communis L. Laboratório Rotacional. Ensino Híbrido.

\begin{abstract}
This work proposes an adaptation to the active methodology called "Rotational Laboratory" and its practices in basic education (Hybrid Education). We start from an initial questioning of the students about the toxicity of the plant species Ricinus communis L., popularly known as castor bean. This questioning constituted a Learning Theme Generator with the main objective of identifying the active principles responsible for toxicity in the dust of the leaves of the plant species and learning from the experimental approach, concepts of Organic Chemistry. In order to seek an answer to the initial question, students rotated between the traditional classroom and the computer and science labs. In this way, the students researched the species and carried out chemical tests to verify the presence of

\footnotetext{
"Doutor em Química de Produtos Naturais pela Universidade Estadual Paulista "Julio de Mesquita Filho" - IQ UNESP- Campus de Araraquara. Coordenador/professor da Universidade Brasil. Supervisor do Programa Institucional de Bolsa de Iniciação à Docência (PIBID) da Universidade Brasil. Tem experiência na área de Química, com ênfase em Química de Produtos Naturais e Educação Química. Fernandópolis, São Paulo. kminine117@gmail.com.
} 
chemical constituents in the powder of the leaves. When thinking about the Rotational Laboratory as a practice, we must consider the fundamental role of technology, as well as the changing role of the teacher who becomes the mediator of the process. Engagement was observed during the execution of activities, autonomy, creativity, motivation to participate in classes and collaborative learning. It was found that the active Rotational Laboratory methodology was important for learning chemical concepts and allowed students to answer the initial question about the toxicity of the plant species.

Keywords: Ricinus communis L. Rotational Laboratory. Hybrid Teaching.

\section{RESUMEN}

Este trabajo propone una adaptación a la metodología activa denominada "Laboratorio Rotacional" y sus prácticas en la educación básica (Educación Híbrida). Partimos de un interrogatorio inicial a los alumnos sobre la toxicidad de la especie vegetal Ricinus communis L., conocida popularmente como ricino. Este cuestionamiento constituyó un Generador de Temas de Aprendizaje con el objetivo principal de identificar los principios activos responsables de la toxicidad en el polvo de las hojas de las especies vegetales y aprender desde el enfoque experimental, conceptos de Química Orgánica. Para buscar una respuesta a la pregunta inicial, los estudiantes rotaron entre el aula tradicional y los laboratorios de informática y ciencias. De esta forma, los estudiantes investigaron la especie y realizaron pruebas químicas para verificar la presencia de constituyentes químicos en el polvo de las hojas. Al pensar en el Laboratorio Rotacional como una práctica, debemos considerar el rol fundamental de la tecnología, así como el rol cambiante del docente que se convierte en el mediador del proceso. Se observó compromiso durante la ejecución de actividades, autonomía, creatividad, motivación para participar en clases y aprendizaje colaborativo. Se encontró que la metodología activa del Laboratorio de Rotación era importante para el aprendizaje de conceptos químicos y permitía a los estudiantes responder a la pregunta inicial sobre la toxicidad de las especies vegetales.

Palabras clave: Ricinus communis L. Laboratorio rotacional. Enseñanza híbrida.

\section{INTRODUÇÃO}

Entende-se o ensino híbrido como uma abordagem pedagógica que combina atividades presenciais e metodologias realizadas por meio das tecnologias digitais e técnicas de ensino que combinam as diferentes tecnologias de informação e comunicação para facilitar o aprendizado dos alunos. É importante entender que as atividades devem ser combinadas de modo que o aluno saia de uma postura passiva frente ao objeto de conhecimento e passe a interagir com as tecnologias da informação e comunicação. Dessa forma, existem diferentes propostas de como combinar essas atividades, focando o processo de aprendizagem no aluno e não mais na transmissão de informação que o professor tradicionalmente realiza. $\mathrm{O}$ ensino híbrido provoca no professor também, a necessidade de refletir sobre a organização das salas de aula, o planejamento pedagógico, entre outros. A escola precisa construir um planejamento das atividades contemplando a reformulação de horários das aulas, organização dos espaços da escola e principalmente priorizar o trabalho interdisciplinar. 
Nesse processo educativo, o professor precisa assumir outra atitude, desenvolvida a partir de uma nova possibilidade, que advenha de uma postura crítica, reflexiva e orientada pela responsabilidade social, atendendo a inserção das tecnologias em sala de aula. O docente precisa ser problematizador e mediador do processo ensino-aprendizagem, sem "perder sua autoridade nem, tampouco, a responsabilidade com a competência técnica dentro de sua área do conhecimento" (MOURA, 2008, p. 30).

$\mathrm{Na}$ proposta de ensino híbrido, o aluno estuda o material em diferentes situações e ambientes, e a sala de aula passa a ser o lugar de aprender ativamente, realizando atividades de resolução de problemas ou projeto, discussões, entre outros, com o apoio do professor e colaborativamente (BACICH, NETO E MELLO, 2015, p. 14).

Podemos ensinar e aprender de inúmeras formas, em todos os momentos, em múltiplos espaços. Híbrido é um conceito rico, apropriado e complicado. Tudo pode ser misturado, combinado, e podemos, com os mesmos ingredientes, preparar diversos "pratos", com sabores muito diferentes (MORAN, 2015).

Nesse tipo de ensino o professor assume uma nova atitude, de modo que passe a ser mediador do processo ensino-aprendizagem. Embora, vez por outra, ainda desempenhe o papel do especialista que possui conhecimentos e/ou experiências a comunicar, no mais desempenhará o papel de orientador das atividades do aluno, de consultor, de facilitador da aprendizagem, de alguém que pode colaborar para dinamizar a aprendizagem do aluno. Desempenhará o papel de quem trabalha em equipe, junto com o aluno, buscando os mesmos objetivos; numa palavra, desenvolverá o papel de mediação pedagógica (MASETTO, 2000, p.142).

O modelo Ensino Híbrido apresenta-se mesclado, em um processo de ensino mais aberto e criativo. É importante saber que a aprendizagem se constrói em um processo equilibrado por meio de uma elaboração coletiva e individual, trabalhando um mundo dinâmico e de diversas linguagens. Trata-se de um modelo de ensino que mescla o melhor dos dois mundos: presencial e o on-line (HARASIM et al, 2005). Enquanto parte do processo de ensino e aprendizagem ocorre em sala de aula, onde os alunos interagem entre si trocando experiências, o método de ensino on-line utiliza meios digitais para que o aluno tenha mais autonomia na forma de aprender (MORAN, 2015). 
De acordo com Bacich et al, 2015, a variedade de recursos utilizados, como vídeos, leituras, trabalho individual e colaborativo, também favorece a personalização do ensino uma vez que nem todos os alunos aprendem da mesma forma.

\section{REFERÊNCIAL TEÓRICO}

As metodologias ativas se apresentam como estratégias pedagógicas que colocam o foco do processo de ensino e aprendizagem no aprendiz, contrastando com a abordagem pedagógica do ensino tradicional, centrada no professor, que transmite informação aos alunos. O fato de elas serem caracterizadas como ativas está relacionado com a aplicação de práticas pedagógicas para envolver os alunos, engajá-los em atividades práticas, nas quais eles são protagonistas da sua aprendizagem.

Assim, as metodologias ativas procuram criar situações de aprendizagem em que os aprendizes façam coisas, coloquem conhecimentos em ação, pensem e conceituem o que fazem, construam conhecimentos sobre os conteúdos envolvidos nas atividades que realizam. Desenvolvam estratégias cognitivas, capacidade crítica e reflexão sobre suas práticas, forneçam e recebam feedback, aprendam a interagir com colegas e professor e explorem atitudes e valores pessoais e sociais (BERBEL, 2011; MORAN, 2015; PINTO et al., 2013).

A implantação de situações que permitam a construção de conhecimento envolve acompanhamento e assessoramento constante do aprendiz no sentido de poder entender quem ele é e o que faz, para ter condições de propor desafios e auxiliá-lo a atribuir significado ao que está realizando. Assim ele consegue processar as informações, aplicando-as, transformando-as, buscando novas informações e, desse modo, construindo novos conhecimentos (VALENTE, 2014).

Os modelos de Rotação por Estações, Laboratório Rotacional e Sala de Aula Invertida seguem o modelo de inovações híbridas sustentadas. Eles incorporam as principais características tanto da sala de aula tradicional quanto do ensino online. Os modelos Flex, A La Carte, Virtual Enriquecido e de Rotação Individual, por outro lado, estão se desenvolvendo de modo mais disruptivo em relação ao sistema tradicional (CHRISTENSEN; HORN; STAKER, 2013).

Nesse trabalho, a metodologia utilizada será o modelo do Laboratório Rotacional adaptado, no qual os alunos utilizarão o espaço da sala de aula e laboratórios (de Informática e 
de Ciências). Serão organizados em grupos e cada um dos quais realizarão uma tarefa, de acordo com os objetivos propostos para a aula.

O Laboratório Rotacional é um modelo de rotação em que dentro de um dado curso ou assunto, os alunos alternam em um horário fixo, ou a critério do professor, entre os locais dentro da escola. Ele consiste em criar dois ambientes de aprendizagem, divididos entre online e off-line (STAKER E CHRISTENSEN, 2015).

Os estudantes usam o espaço da sala de aula e laboratórios. O modelo de laboratório rotacional começa com a sala de aula tradicional, em seguida adiciona uma rotação para computador ou laboratório de ensino. Os laboratórios rotacionais frequentemente aumentam a eficiência operacional e facilitam o aprendizado personalizado, mas não substituem o foco nas lições tradicionais em sala de aula (BACICH; NETO; TREVISANI, 2015).

\section{METODOLOGIA}

Propusemos aqui uma adaptação à metodologia do Laboratório Rotacional. Os alunos deverão utilizar ambientes diferentes, por exemplo, sala de aula, sala de informática e laboratório de Ciências a fim de apreender conceitos químicos a partir do estudo fitoquímico das folhas da mamona (Ricinus communis L.) e procurar responder ao questionamento formulado inicialmente: "Por que a planta mamona é tão tóxica?"

Este trabalho caracterizou-se como uma pesquisa de cunho qualitativo, na qual se utilizou os pressupostos teóricos-metodológicos da pesquisa participante. Os procedimentos técnicos da investigação possuem aproximações com a pesquisa participante, em razão do envolvimento com os sujeitos e com o lócus da pesquisa. Esse tipo de pesquisa está direcionado à união entre conhecimento e ação, visto que a prática (ação) é um componente essencial também do processo de conhecimento e de intervenção na realidade. Isso porque, à medida que a ação acontece, descobrimos novos problemas antes não pensados, cuja análise e consequente resolução também sofrem modificações, dado o nível maior de experiência tanto do pesquisador quanto de seus companheiros da comunidade (PRODANOV e FREITAS, 2013).

Trabalhou-se com alunos do $3^{\circ}$ Ano do Ensino Médio de uma Escola da Rede Estadual de São Paulo, em 2019 (EE. Carlos Barozzi), município de Fernandópolis-SP. Destacamos que a escola conta com laboratórios de informática e Ciências bastante equipados. A sala escolhida foi a $3^{\text {a }}$ Série A, do período da manhã, e contava com 30 alunos e duas aulas 
semanais de Química de 45 minutos. Para o trabalho foram montados 06 (seis) grupos com 05 alunos. Utilizou-se como técnica, a metodologia de ensino híbrido denominada Laboratório Rotacional. O modelo de laboratório rotacional é diferente do modelo de rotação por estações, porque os alunos rotacionam entre diferentes espaços, ao invés de ficarem em uma sala de aula com diferentes estações de aprendizagem. Propusemos uma adaptação ao modelo, uma vez que faríamos a rotação em dois laboratórios diferentes (Informática e Ciências), além das aulas em sala. Foram utilizadas também aulas em dias diferentes e não uma única aula. Como tema gerador, utilizamos a investigação fitoquímica do pó proveniente das folhas da espécie vegetal Ricinus communis L., Euphorbiaceae, popularmente conhecida como mamona. Esse tema partiu de interesse imediato de um aluno cujo pai trabalha numa miniusina de processamento da mamona. Segundo o aluno, o pai comentou que a torta de mamona contém alto teor de proteína, mas não tem sido utilizada como alimento animal devido à presença de toxinas e alergênicos. O comentário provocou uma ampla discussão sobre o tema, despertando a curiosidade dos demais alunos. E uma pergunta surgiu: Que substâncias químicas tem a folha da mamona? Por que é tóxica?

A fim de estimular ainda mais a curiosidade dos alunos e tornar a aprendizagem mais prazerosa, elaborou-se uma sequência de aulas (10 no total), em cinco dias não consecutivos para investigar quais constituintes químicos estão presentes na folha da mamona e investigar no laboratório quais são as principais classes de substâncias potencialmente ativas no pó proveniente das folhas. Nesse processo, houve alternância entre os diferentes espaços (sala de aula, sala de Informática e laboratório de Ciências).

Num primeiro momento, os alunos foram informados que 03 grupos, denominado $G 1$, G2 e $G 3$ ficariam na sala de aula com o professor. Os outros 03 grupos restantes $(G 4, G 5$ e G6) seriam encaminhados para o laboratório de Informática e seriam acompanhados pelo técnico responsável por esse espaço de ensino. Foram informados ainda, que na aula seguinte haveria troca entre os grupos. Os grupos $G 4, G 5$ e $G 6$ fariam a aula em sala e os grupos $G 1$, G2 e G3 estariam trabalhando no laboratório de informática. Ao final desse primeiro momento (uma terceira aula), todos os grupos estariam presentes em sala de aula para fazer a compilação das informações levantadas nas pesquisas feitas no laboratório de informática. $\mathrm{O}$ professor utilizou a aula teórica em sala para dialogar com os alunos sobre o tema plantas medicinais e plantas tóxicas, entre elas a mamona. Nesse processo, buscou-se o conhecimento prévio dos alunos, ou seja, o que o aluno já sabia (conceitos, proposições, princípios, fatos, ideias, imagens, símbolos). Esse levantamento é fundamental na teoria da aprendizagem 
significativa, uma vez que se constitui como determinante do processo de aprendizagem, pois é significativo por definição, base para a transformação dos significados lógicos dos materiais de aprendizagem, potencialmente significativos, em significados psicológicos (AUSUBEL, NOVAK, HANESIAN, 1980; AUSUBEL, 2003).

O professor aproveitou o momento de aula em sala para apresentar o pó semifino das folhas da mamona. Para isso o professor coletou as folhas da mamona previamente à realização da aula. Explicou que o material vegetal fora dividido em pedaços de aproximadamente 2 centímetros de comprimento, submetidos à secagem em temperatura ambiente e a seguir pulverizado em moinho de facas e martelos até a obtenção de um pó semifino (FARMACOPÉIA, 1959). Cada grupo de alunos recebeu um frasco de vidro contendo cerca de $200 \mathrm{~g}$ de pó da folha para realização do trabalho de laboratório.

Em relação aos grupos que foram conduzidos ao laboratório de informática, foi dada uma comanda para que pesquisassem sobre a espécie vegetal Ricinus communis L. O objetivo era buscar em sites e artigos especializados a sinonímia vulgar da espécie, nome científico da mamona, aspectos químicos da espécie vegetal (constituintes químicos), ações farmacológicas e usos das folhas da mamona e toxicidade.

Os alunos foram incentivados a buscar essas informações e registrar em seus cadernos. À medida que as informações iam sendo coletadas, os resultados eram socializados entre os diferentes grupos e as informações iam sendo completadas. Esse momento foi bastante rico para ampliação dos conhecimentos sobre a espécie vegetal. Os diferentes grupos escreveram os nomes químicos das substâncias presentes em folhas e copiaram suas fórmulas estruturais e as funções orgânicas presentes foram indicadas.

Na sequência, encaminhou-se o trabalho da seguinte forma: aula 04 (grupos G1 a G3) ficaram em sala para uma roda de conversa sobre os resultados obtidos até então e esclarecimento de dúvidas que os alunos ainda tinham sobre o que fora pesquisado no primeiro momento do trabalho. Os grupos $G 4$ a $G 6$ foram conduzidos ao laboratório de Ciências para realização dos testes químicos com o pó das folhas da mamona. Receberam o roteiro experimental e na bancada já estavam dispostas as vidrarias e reagentes necessários ao trabalho experimental. Nesse momento, foram acompanhados e orientados por alunos de graduação em Química pertencentes ao Projeto PIBID (Programa Institucional de Bolsas de Iniciação à Docência) do Ministério da Educação. Os grupos G4 a G6 fizeram testes para detectar a possível presença das seguintes classes de substâncias: alcalóides, antraderivados, cumarinas, esteroides (MATOS, MATOS, 1989). Na aula 05, houve novamente a troca dos 
grupos, fazendo a alternância entre a sala de aula e o laboratório de Ciências. Os grupos G1 a G3, realizaram testes para identificar: flavonoides, saponinas, glicosídeos cardiotônicos, taninos (MATOS, MATOS, 1989).

$\mathrm{Na}$ aula $06, G 1$ a $G 3$ permaneceram em sala para nova roda de conversa sobre os testes químicos realizados e os grupos $G 4$ a $G 6$ foram encaminhados à sala de informática e orientados a utilizar um aplicativo gratuito (SketchEl) para desenhar as fórmulas estruturais dos compostos orgânicos anteriormente pesquisados. Os alunos foram acompanhados pelo técnico de informática e pelos alunos do PIBID em todas as etapas de construção das fórmulas estruturais. Na aula seguinte (aula 07), os alunos se alternaram novamente e os Grupos G1 e G3 construíram as fórmulas estruturais no laboratório de informática.

Utilizou-se de mais uma aula (aula 08) para a compilação das informações e trocas de ideias entre os alunos. A riqueza de material que foi registrado por cada grupo de alunos possibilitou a troca de experiências em momentos bastante significativos. Esse processo possibilitou a troca de informações e socialização de forma democrática estabelecendo uma organização diferenciada de trabalho aonde o próprio grupo construía seu conhecimento e refletia sobre suas práticas, sendo que nessa interação e intervenção, o professor atuava como mediador. Mais duas aulas foram utilizadas para discussões acerca do trabalho realizado, montagem do portfólio e construção de mapas conceituais, os quais foram utilizados como avaliação final do trabalho.

\section{ANÁLISE E RESULTADOS}

Essa pesquisa buscou trabalhar um tema de interesse dos alunos a partir do estudo da mamona (Ricinus communis L.). Utilizou-se uma metodologia de ensino híbrido denominado Laboratório Rotacional. A sala foi dividida em 06 grupos ( $G 1$ a $G 6)$ que se alternavam entre aula em sala e aulas práticas nos laboratórios de Informática e de Ciências.

Após a alternância entre os espaços da sala de aula e laboratórios, uma aula era reservada para a apresentação e discussão dos resultados entre os alunos e o professor. Nesse processo podia-se acompanhar a evolução do pensamento dos alunos e observar a diferenciação progressiva entre as ideias iniciais e os novos conceitos que afloravam à medida que avançavam na busca das informações (aprendizagem significativa). À medida em que a aprendizagem significativa ocorria, conceitos eram desenvolvidos, elaborados e diferenciados em decorrência de sucessivas interações (Diferenciação progressiva). Dessa forma as ideias 
mais gerais e mais inclusivas da disciplina devem ser apresentadas no início para, depois irem sendo progressivamente diferenciadas. Em termos de detalhe e especificidade é mais fácil para o ser humano captar aspectos diferenciados de um todo mais inclusivo previamente aprendido, do que chegar ao todo a partir de suas partes diferenciadas. A Reconciliação integrativa consiste em explorar relações entre ideias, apontar similaridades e diferenças importantes, reconciliar discrepâncias reais ou aparentes. O conteúdo deve não só proporcionar a diferenciação progressiva, mas também explorar, explicitamente, relações entre proposições e conceitos, chamar atenção para diferenças e similaridades importantes e reconciliar inconsistências reais ou aparentes (AUSUBEL, 1980).

Dessa forma, os alunos (G1 e G2) descreveram a espécie Ricinus communis L.: "Conhecida como carrapateira, enxerida, rícino, palma-de-cristo ou mamona, a Ricinus communis L., pertencente à família Euphorbiaceae (Figura 1). O nome Ricinus, de origem latina, significa carrapato, devido à forma das suas sementes que remetem ao ácaro. Sua origem ainda é desconhecida, porém estima-se que tenha origem no continente africano ou asiático (SOUZA, 2012). A mamona (Ricinus communis L.) é conhecida popularmente por seus efeitos tóxicos, como também pela sua importância econômica. A cultura da mamona é uma alternativa para a produção de biocombustível, não tóxico, biodegradável. Seu uso promove redução da emissão de gases tóxicos no escapamento dos veículos além da redução de gases que para o efeito estufa, pode ser um potencial no resgate econômico e social das famílias rurais (RIZZO, 2005). As suas sementes contêm ricinina, um alcalóide extremamente tóxico para animais e seres humanos, sendo que as folhas possuem uma menor concentração da toxina. As sementes causam problemas gastrointestinais e as folhas podem causar problemas neuromusculares, quando ingeridas. Os sintomas da intoxicação em animais geralmente aparecem após algumas horas ou poucos dias (FILHO SAVY, 2005)”.

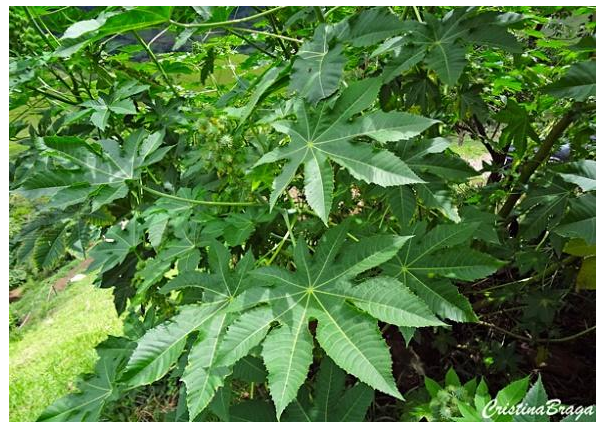

Figura 1 - Ricinus communis L. (https://www.floresefolhagens.com.br/mamona-ricinus-communis/). 
Os grupos $G 3$ e $G 4$ apresentaram dados sobre a constituição química da espécie Ricinus communis L., a partir da pesquisa que fizeram pela internet em artigos científicos: "Foram isolados e identificados dois alcaloides, ricinina e $\mathrm{N}$-dimetilricina e seis glicosídeos flavonoídicos, quenferol-3-O-beta-D-xilopiranosídio, quenferol-3-O-beta-D-glicopiranosídeo, quenferol-3-O-beta-rutinosídeo, quercetina-3-O-betaD-glicopiranosídeo (isoquercetina) e quercetina-3-O-beta-D-rutinosídeo (rutina) (KANG et al., 1985)”.

Utilizando-se do aplicativo gratuito SketchEl (https://pplware.sapo.pt/software/sketchel-editor-de-moleculas-open-source/), construíram as moléculas indicadas no artigo. Esse processo foi bastante rico em discussões, uma vez que puderam entender conceitos importantes em química, tais como tetravalência do átomo de carbono, ângulo de ligações, obtenção da fórmula molecular a partir da fórmula estrutural, identificação dos grupamentos funcionais, isomeria. A Figura 2, mostra as fórmulas estruturais construídas a partir do aplicativo baixado<smiles>COc1ccn(C)c(=O)c1C#N</smiles>

(1)<smiles>O=C(Cl)Oc1c(-c2ccc(O)c(O)c2)oc2cc(O)cc(O)c2c1=O</smiles>

(2)<smiles>Cc1ccc(-c2oc3cc(O)cc(O)c3c(=O)c2OCCCCCCCCCCCCO)cc1O</smiles>

Figura 2 - Constituintes químicos isolados da espécie Ricinus communis L. (1) N-dimetilricinina, (2) quercetina-3-xilopiranosídio, (3) quenferol-3-glicopiranosídio, (4) quenferol-3-rutinosídio. (Fonte: elaborado pelo autor) 
Nas folhas de Ricinus communis L. foram detectados ainda, ácido gálico, ácido elágico, ácido ferúlico, ácido para-cumárico e os flavonoides rutina, quercetina e isoquercetina (DUKE, 1987). Algumas dessas estruturas foram desenhadas e estão indicadas na Figura 3.<smiles>O=C(O)c1cc(O)c(O)c(O)c1</smiles>

(1)

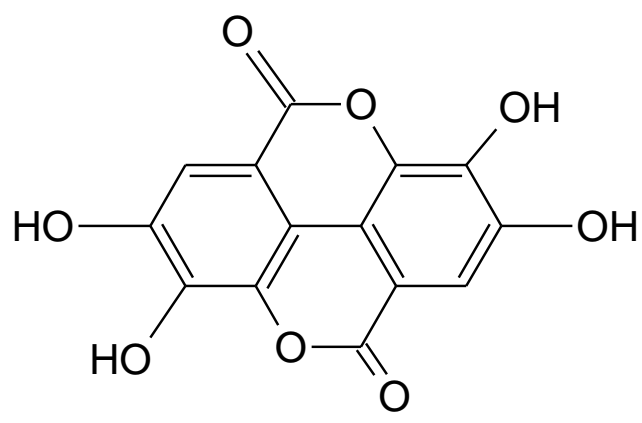

(2)

Figura 3 - Constituintes químicos isolados das folhas da espécie Ricinus communis L. (1) ácido gálico, (2) ácido elágico. (Fonte: elaborado pelo autor)

Os grupos $G 5$ e $G 6$ apresentaram os dados obtidos a partir das reações de identificação das classes de substâncias presentes nas folhas de Ricinus communis L. A apresentação dos resultados dos testes químicos se deu após a discussão entre todos os grupos sobre as reações químicas realizadas e a identificação da presença das classes de substâncias a partir das reações de coloração, precipitação. Conceitos como evidências das transformações químicas, proporcionalidade nas reações, escrita de fórmulas químicas, soluto, solvente, solubilidade, concentração de soluções eram aprendidos e discutidos no transcorrer das atividades experimentais. Os resultados obtidos na abordagem fitoquímica das folhas de Ricinus communis L. feita pelos alunos, encontram-se na Tabela 1.

Tabela 1 - Classes de substâncias presentes no pó das folhas de Ricinus communis L.

\begin{tabular}{ll}
\hline Classes de substâncias & Resultados \\
\hline Alcalóides & + \\
Antraderivados & - \\
Cumarinas & - \\
Esteróides & + \\
Flavonóides & + \\
Saponinas & + \\
Glicosídeos cardiotônicos & - \\
Taninos & + \\
\hline
\end{tabular}

$(+)=$ presença; $(-)=$ ausência. 
A partir das reflexões teóricas, é possível corroborar que a metodologia do Laboratório Rotacional emerge como uma inovação sustentada em relação à sala de aula tradicional. A aplicação do ensino híbrido, no submodelo de Laboratório Rotacional, apresentou boa aceitação por parte dos estudantes, apesar de ser uma metodologia ainda desconhecida pelos mesmos. Também favoreceu aspectos como o engajamento, a autonomia, a criatividade, a motivação na participação das aulas e, o aprender de forma colaborativa. Essa metodologia também foi importante porque possibilitou diagnosticar os conhecimentos prévios dos alunos e detectar as deficiências conceituais de maneira rápida e satisfatória, consolidando o processo ensino-aprendizagem. Os resultados obtidos no transcorrer das atividades foram registrados em portfólios, o que permitiu uma avaliação processual bastante efetiva. O mais importante é que a metodologia utilizada permitiu aos alunos responder ao questionamento inicial: "Por quê a espécie vegetal mamona é tão tóxica?" Os alunos entenderam que a presença de inúmeros princípios ativos no pó das folhas, tais como os detectados pela experimentação realizada e os indicados na literatura pesquisada, são os responsáveis pela toxicidade da espécie vegetal Ricinus communis L. (mamona). A técnica de Laboratório Rotacional, permitiu também, que os alunos aprendessem significativamente conceitos químicos relevantes e se apropriassem da tecnologia para pesquisa científica e aprofundamento do tema inicialmente proposto.

No ensino de química, ao mediar os conteúdos com a tecnologia, melhora as formas de apresentação e exploração, enriquecendo e inovando as aulas com métodos mais dinâmicos e interativos, despertando no aluno a busca pela informação. Estudiosos afirmam que o uso de tecnologia no ensino da química é um recurso didático para melhorar aulas, proporcionando aos alunos uma aprendizagem significativa (LOCATELLI, 2018).

Dessa forma, o processo vivenciado reforça a relevância de aulas que mobilizem os educandos a experimentarem, a construírem e testarem hipóteses, a pesquisarem, no ambiente escolar e em outros espaços, rompendo com a tradição das aulas expositivas e dos exercícios que requerem respostas acabadas. Os conteúdos de Ciências não precisam ser desenvolvidos apenas na sala de aula, na sala de Ciências, no laboratório de informática, podem ocorrer aulas nos ambientes externos à escola, parques, ruas, viagens, por exemplo, ou realizar ações para explicar as consequências da poluição para o planeta, do uso dos agrotóxicos para a saúde, entre outros (SARTORI, LONGO, 2021). 

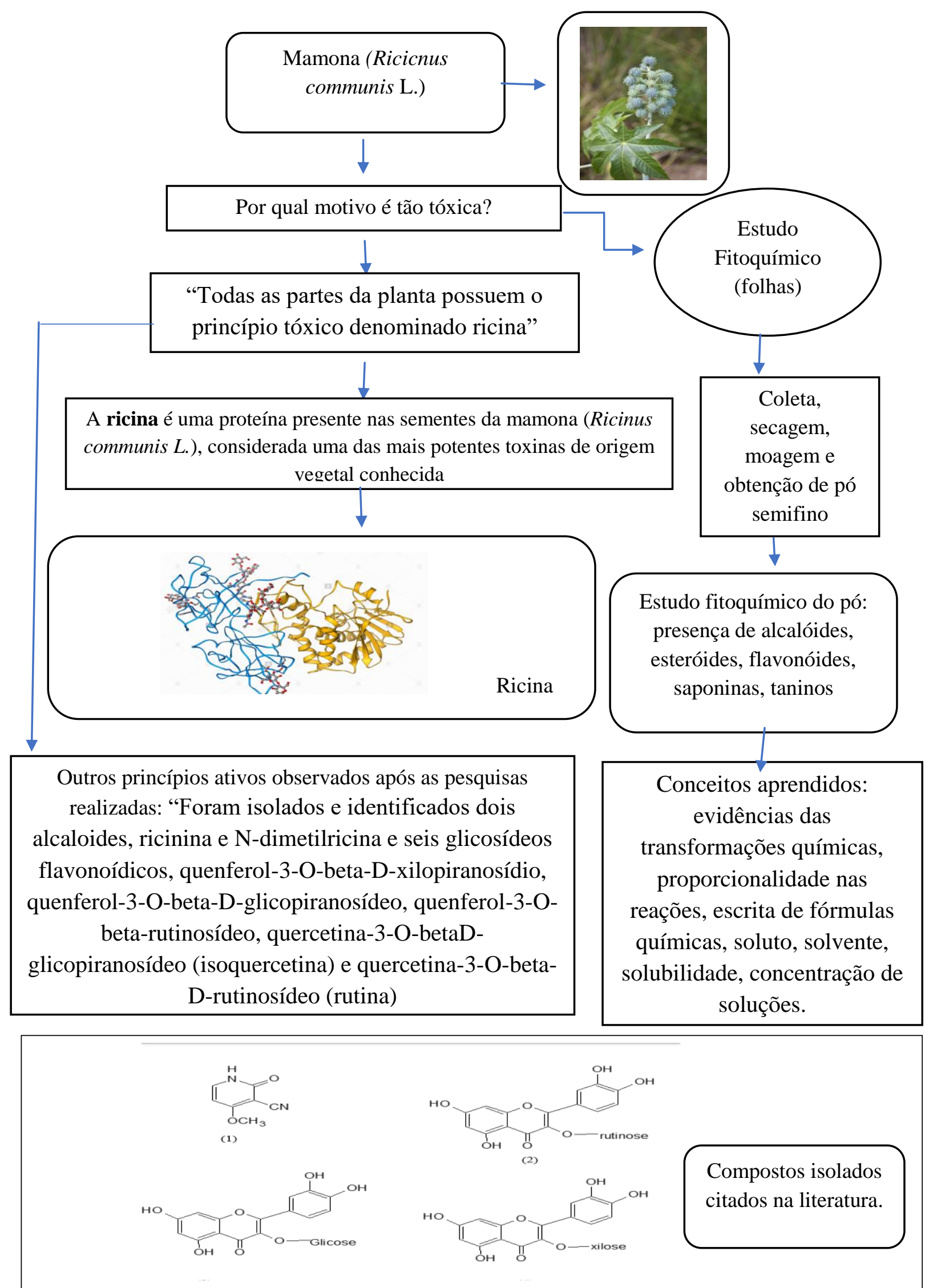

Figura 4 - Exemplo de Mapa Conceitual construído pelos alunos. 


\section{CONSIDERAÇÕES}

A partir da metodologia ativa do Laboratório Rotacional, os alunos puderam concluir que nas folhas de Ricinus communis L. existem uma variedade de substâncias, muitas das quais são potencialmente tóxicas. Os alunos trouxeram ainda as informações da literatura: "Todas as partes da planta possuem o princípio tóxico denominado ricina. Todavia, as sementes, contidas no interior dos frutos apresentam maior concentração e causam a maioria das intoxicações seja pela ingestão de forma acidental ou por fome, cursando graves perturbações digestivas. Ainda, a ingestão de folhas e pericarpo pode provocar sinais neurológicos agudos caracterizados por andar desequilibrado, tremores musculares, sialorreia, eructação excessiva e morte rápida (TOKARNIA et al., 2012)”.

Todas as informações coletadas e as discussões que ocorriam à medida que o trabalho avançava, eram registradas em portfólios e eram construídos Mapas Conceituais (Figura 4). O professor e bolsistas do PIBID atuaram como mediadores na construção do portfólio e dos Mapas Conceituais estando aberto às indagações dos alunos e estimulando que relatassem o que haviam vivenciado e observado.

Desta forma o modelo de Laboratório Rotacional, aplicado nesse estudo, teve início com a sala de aula tradicional, sendo na sequência indicada as rotações para os laboratórios de Informática e Ciências. Evidenciou-se que a técnica de Laboratório Rotacional aumentou a eficiência operacional e facilitou o aprendizado de conceitos químicos pelos alunos, acrescido do fato que o tema partiu do interesse manifestado pelos alunos sobre a toxicidade da espécie vegetal e propiciou responder a indagação inicial dos alunos sobre o "Por que a planta mamona é tão tóxica?".

\section{REFERÊNCIAS}

AUSUBEL, David P.; NOVAK, Joseph D.; HANESIAN, Helen. Psicologia Educacional. 2 ed. Rio de Janeiro: Interamericana, 1980.

AUSUBEL, David. P. Aquisição e Retenção de Conhecimentos: Uma Perspectiva Cognitiva. 1 ed. Lisboa: Plátano, 2003. 
BACICH, Lilian; NETO, Adolfo Tanzi; TREVISANI, Fernando de Melo (Org.). Ensino híbrido: Personalização e tecnologia na educação. Porto Alegre: Penso, 2015. p.272.

BERBEL, Neusi Aparecida Navas. As metodologias ativas e a promoção da autonomia de estudantes. Ciências Sociais e Humanas, Londrina, v. 32, n. 1, p. 25-40, jan./jun. 2011. Acesso em: 21 fev. 2020. Disponível em:

https://edisciplinas.usp.br/pluginfile.php/5437015/mod_resource/content/1/As\%20metodologi as $\% 20$ ativas $\% 20 \mathrm{e} \% 20 \mathrm{a} \% 20$ promoc $\% \mathrm{CC} \% \mathrm{~A} 7 \mathrm{a} \% \mathrm{CC} \% 83 \mathrm{o} \% 20 \mathrm{da} \% 20$ autonomia $\% 20 \mathrm{de} \% 20 \mathrm{e}$ studantes\%20-\%20Berbel.pdf

CHRISTENSEN, Clayton.; HORN, Michael; STAKER, Heather. Ensino híbrido: uma inovação disruptiva? Uma introdução à teoria dos híbridos. Maio de 2013.

DUKE JA. Handbook of medicinal herbs. Florida: CRC Press., 1987. p. 677.

FARMACOPEIA DOS ESTADOS UNIDOS DO BRASIL. 2.ed. São Paulo: Indústria Gráfica Siqueira, 1959.

FILHO, Ângelo Savy. BANZATTO, Nicolau.; PETTINELLI, Júnior. A. Potencial dos Resíduos Vegetais da Cultura da Mamoneira (Ricinus communis L.), na Substituição de Insumos Agrícolas. Revista de Agricultura, Piracicaba, 64(2): 241-254, 1989. Disponível em: https://www.pucpr.br/wp-content/uploads/2017/10/ensino-hibrido_uma-inovacaodisruptiva.pdf. Acesso em: 31 de mar. 2021.

HARASIM, Linda et al. Redes de Aprendizagem: Um Guia para o ensino e aprendizagem online. São Paulo: Editora SENAC, 2005. Disponível em:

https://www.redalyc.org/pdf/1935/193517360011.pdf. Acesso em: 12 de jun. 2020.

HORN, Michael B.; STAKER, Heather; CHRISTENSEN, Clayton. Blended: usando a inovação disruptiva para aprimorar a educação. Penso Editora, 2015.

KANG S. San.; CORDELL Geoffrey., SOEJARTO Dijaja., FONG Harry. Alkaloids and flavonoids from Ricinus communis. J. Nat.Prod, 1985. p.48(1): 155-156. Disponível em: https://pubs.acs.org/doi/abs/10.1021/np50037a041. Acesso em: 22 de jul. 2020.

LOCATELLI, Tamiris. A Utilização de Tecnologias no Ensino da Química. Revista Científica Multidisciplinar Núcleo do Conhecimento. Ano 03, Ed. 08, Vol. 04, pp. 5-33, 2018. Disponível em: https://www.nucleodoconhecimento.com.br/educacao/tecnologias-no-ensino. Acesso em: 10 de jan. 2022.

MASETTO, Marcos T. Mediação pedagógica e o uso da tecnologia. In: Moran, José Manuel (org.). Novas tecnologias e mediação pedagógica. Campinas, SP: Papirus, 2000. 
MATOS, J. M. D. MATOS, M.E.O. Farmacognosia: curso teórico-prático. Fortaleza: UFC, 1989.

MORAN, José. Mudando a educação com metodologias ativas. In: Carlos Alberto de Souza e Ofelia Elisa Torres Morales (orgs.). Coleção Mídias Contemporâneas. Convergências Midiáticas, Educação e Cidadania: aproximações jovens. Vol. II. PG: Foca FotoPROEX/UEPG, 2015.

MOURA, D. H. A formação de docentes para a educação profissional e tecnológica. Revista Brasileira da Educação Profissional e Tecnológica. Brasília, MEC, Setec, v. 1, n. 1, p. 23- 37, jun. 2008. Disponível em: https://home.unicruz.edu.br/mercosul/pagina/anais/2018/. Acesso em: 10 de jan. 2022.

PINTO, Antônio Sávio da Silva et al. O Laboratório de Metodologias Inovadoras e sua pesquisa sobre o uso de metodologias ativas pelos cursos de licenciatura do UNISAL, Lorena: estendendo o conhecimento para além da sala de aula. Revista de Ciências da Educação, São Paulo, v. 2, n. 29, p. 67-79, jun./dez. 2013. Disponível em:

http://revista.unisal.br/ojs/index.php/educacao/article/view/288. Acesso em: 02 de ago. 2020.

PRODANOV, Cleber Cristiano; FREITAS, Ernani Cesar de. Pesquisa Científica. In:

Método do Trabalho Científico: Métodos e Técnicas da Pesquisa e do Trabalho Acadêmico.

2. ed. Novo Hamburgo: Feevale, cap. 3, p. 42-118, 2013. Disponível em:

https://aedmoodle.ufpa.br/pluginfile.php/291348/mod_resource/content/3/2.1-E-book-

Metodologia-do-Trabalho-Cientifico-2.pdf. Acesso em: 08 de ago. de 2020.

RIZZO, M.R., 2005 [online]. O biodiesel a partir da mamona é viável? Disponível em: https://www.biodieselbr.com/artigos/mamona/ga-biodiesel-base-mamona. Acesso em: 19 abr. 2021.

SARTORI, J.; LONGO, M. PRÁTICAS INVESTIGATIVAS NO ENSINO DE CIÊNCIAS NA EDUCAÇÃO BÁSICA. REAMEC - Rede Amazônica de Educação em Ciências e Matemática, [S. l.], v. 9, n. 3, p. e21075, 2021. DOI: 10.26571/reamec.v9i3.11976.

Disponível em: https://periodicoscientificos.ufmt.br/ojs/index.php/reamec/article/view/11976. Acesso em: 10 jan. 2022.

SOUZA, Felipe Vieira de. Expressão de genes em resposta a estresse por restrição hídrica em sementes de Ricinus communis L. (Euphorbiaceae). 2012. 76f. Dissertação (Mestrado) - Programa de Pós-graduação em Biotecnologia. Universidade Federal da Bahia, Salvador, 2012. Disponível em:

https://repositorio.ufba.br/ri/bitstream/ri/11906/1/Disserta\%C3\%A7\%C3\%A3o_ICS_Felipe\% 20Souza.pdf. Acesso em: set. de 2020. 
TOKARNIA Carlos.Hubinger; BRITO Marilene de Farias; BARBOSA José Diomedes; PEIXOTO Paulo Vargas; DOBEREINER Jurgen. Plantas tóxicas do Brasil para animais de produção. 2.ed. Rio de Janeiro: Editora Helianthus, p.119-124 \& 284-285, 2012. Disponível em: https://www.worldcat.org/title/plantas-toxicas-do-brasil-para-animais-deproducao/oclc/881371461. Acesso em: 21 de out. 2020.

VALENTE, José Armando. A Comunicação e a Educação baseada no uso das Tecnologias Digitais de Informação e Comunicação. Revista UNIFESO - Humanas e Sociais, vol. 1, n. 1, 2014, pp. 141-166. Disponível em: https://www.unifeso.edu.br. Acesso em: 10 de jan. 2022.

\section{APÊNDICE 1}

\section{AGRADECIMENTOS}

Aos bolsistas do PIBID da Universidade Brasil e à Escola Carlos Barozzi.

\section{FINANCIAMENTO}

"Não se aplica"

\section{CONTRIBUIÇÕES DE AUTORIA}

"Não se aplica".

\section{CONFLITOS DE INTERESSE}

O autor declarara não haver nenhum conflito de interesse de ordem pessoal, comercial, acadêmico, político e financeiro referente a este manuscrito.

\section{DISPONIBILIDADE DE DADOS DE PESQUISA}

O conjunto de dados que dá suporte aos resultados da pesquisa foi publicado no próprio artigo.

\section{CONSENTIMENTO DE USO DE IMAGEM}

"Não se aplica."

\section{APROVAÇÃO DE COMITÊ DE ÉTICA EM PESQUISA \\ "Não se aplica."}

\section{COMO CITAR - ABNT}

MININEL, Francisco José. Estudo fitoquímico da Mamona: Uso da técnica do laboratório rotacional adaptado. REAMEC - Rede Amazônica de Educação em Ciências e Matemática. Cuiabá, v. 10, n., 1, e22006, jan./abr., 2022. http://dx.doi.org/10.26571/reamec.v10i1.12916.

\section{COMO CITAR - APA}

Mininel, F. J. (2022). Estudo fitoquímico da Mamona: Uso da técnica do latoratório rotacional adaptado. REAMEC - Rede Amazônica de Educação em Ciências e Matemática, 10(1), e22006. http://dx.doi.org/10.26571/reamec.v10i1.12916.

\section{LICENÇA DE USO}

Licenciado sob a Licença Creative Commons Attribution-NonCommercial 4.0 International (CC BY-NC 4.0). Esta licença permite compartilhar, copiar, redistribuir o manuscrito em qualquer meio ou formato. Além disso, permite adaptar, remixar, transformar e construir sobre o material, desde que seja atribuído o devido crédito de autoria e publicação inicial neste periódico.

\section{DIREITOS AUTORAIS}

Os direitos autorais são mantidos pelos autores, os quais concedem à Revista REAMEC - Rede Amazônica de Educação em Ciências e Matemática - os direitos exclusivos de primeira publicação. Os autores não serão remunerados pela publicação de trabalhos neste periódico. Os autores têm autorização para assumir contratos adicionais separadamente, para distribuição não exclusiva da versão do trabalho publicada neste periódico (ex.: publicar em repositório institucional, em site pessoal, publicar uma tradução, ou como 
capítulo de livro), com reconhecimento de autoria e publicação inicial neste periódico. Os editores da Revista têm o direito de proceder a ajustes textuais e de adequação às normas da publicação.

\section{PUBLISHER}

Universidade Federal de Mato Grosso. Programa de Pós-graduação em Educação em Ciências e Matemática (PPGECEM) da Rede Amazônica de Educação em Ciências e Matemática (REAMEC). Publicação no Portal de Periódicos UFMT. As ideias expressadas neste artigo são de responsabilidade de seus autores, não representando, necessariamente, a opinião dos editores ou da referida universidade.

\section{EDITOR}

Patrícia Rosinke (D) 0

\section{HISTÓRICO}

Submetido: 31 de agosto de 2021.

Aprovado: 08 de janeiro de 2022.

Publicado: 19 de janeiro de 2022. 